
\title{
СТАНОВЛЕНИЕ И РАЗВИТИЕ ЛЕСНОГО КЛАСТЕРА ЦФО НА СОВРЕМЕННОМ ЭТАПЕ ЭКОНОМИЧЕСКОГО РАЗВИТИЯ
}

\section{FORMATION AND DEVELOPMENT OF THE CENTRAL FEDERAL DISTRICT FOREST CLUSTER AT THE PRESENT STAGE OF ECONOMIC DEVELOPMENT}

\section{Yu. Mindlin}

Summary: This article focuses on the fact that one of the main tasks at the present stage of development of the national economy is to improve the efficiency of the functioning of regions (Federal districts). The solution to this problem involves the rational use of the production and human potential of the regions, the use of modern marketing tools and progressive forms of territorial management. The cluster concept has gradually gained worldwide recognition, as the evolutionary development of cluster formations of different types has led to the effective functioning of enterprises in the regions, creating new jobs, increasing incomes and improving the living standards of the population. The study of the processes of organization/formation and functioning of cluster formations by many scientists of the world has made it possible to find out the essence of clusters, their types, identify and classify the factors that determine the effectiveness of their activities, and, consequently, develop recommendations for the use of clusters in specific economic conditions of other countries. Studies of the socio-economic development of the Central Federal district, its resource potential and the main trends in economic growth have found that priority areas remain, first of all, agriculture and forestry, tourism and recreation, and there are all prerequisites for creating cluster formations in the processing industry.

Keywords: cluster, competitiveness, automotive industry, development, partnership, structure.

\author{
Миндлин Юрий Борисович \\ К.э.н., дочент, ФГБОУ ВО «Московская государственная \\ академия ветеринарной медицины \\ и биотехнологии имени К.И. Скрябина» \\ mindliny@mail.ru
}

Аннотация: В данной статье акцентируется внимание на том, что одной из основных задач на современном этапе развития отечественной экономики является повышение эффективности функционирования регионов (федеральных округов). Решение этой задачи предусматривает рациональное использования производственного и человеческого потенциала регионов, применение современных маркетинговых инструментов и прогрессивных форм управления территориальным хозяйством. Кластерная концепция постепенно получила всемирное признание, поскольку эволюционное развитие кластерных образований разных типов привел к эффективному функционированию предприятий в регионах, создание новых рабочих мест, увеличение доходов и повышение жизненного уровня населения.

Исследование процессов организации/формирования и функционирования кластерных образований многими учеными мира дало возможность выяснить сущность кластеров, их типы, выявить и классифицировать факторы, обусловливающие эффективность их деятельности, а, следовательно, разработать рекомендации по использованию кластеров в конкретных экономических условиях других стран. Проведенные исследования социально-экономического развития Центрального федерального округа, его ресурсного потенциала и основных тенденций экономического роста обнаружили, что приоритетными сферами остаются, прежде всего, сельское и лесное хозяйства, туризм и рекреация и есть все предпосылки для создания кластерных образований в сфере перерабатывающей промышленности.

Ключевые слова: forest, forestry, Central Federal district, cluster, percentage of forest area, development guidelines.

морепродуктов на европейский центр свежей и охлажденной рыбы. Оставаться морским кластером, он смог создать добавленную стоимость и усилить конкурентоспособность за счет логистических инноваций, одновременного использования морского и воздушного портов.

Важным фактором успешности кластеров является способность к изменениям и адаптация. Высокий уровень специализации кластеров делает и уязвимыми перед экономическими кризисами на определенных в определенных регионах. Обеспечение открытости кластера и международное сотрудничество позволяют избегать этого риска.

Исследование деятельности европейских кластеров позволили определить следующие факторы их успешного формирования ("prerequisites" forthe emergence of 
clusters) в порядке приоритетности:

- Наличие квалифицированной рабочей силы;

- Сильные связи в сети акторов кластера;

- Наличие известных университетов и исследовательских центров;

- Традиции и исторические предпосылки;

- Структура промышленности;

- Местная политика.

Среди событий, которые способствовали развитию кластеров (triggering events) назывались:

- Участие в кластере ведущих фирм;

- Меры кластерной политики;

- Исторические события, в частности войны.

K факторам «самовозрастания» кластеров (selfaugmenting processes) относятся:

- Аккумуляция человеческого капитала;

- Кооперация между фирмами;

- Выгоды от совместного расположения наряду с другими фирмами.

Эффективное использование лесов и лесосырьевых ресурсов является одним из определяющих факторов устойчивого развития и жизнеобеспечения всех регионов Лесное хозяйство и смежные с ним отрасли промышленного производства, развитие которых тесно связано с наличием лесоресурсного потенциала, традиционно занимают ведущее место в экономике региона и имеют все предпосылки для создания лесопромышленного кластера, прежде всего, в пределах горной и предгорной природно-экономических зон региона, где сохранились глубокие исторические трудовые традиции в сфере лесного хозяйства и лесной промышленности.

Анализ семнадцати областей Центрального федерального округа России по общей территорией и показателем лесистости (табл. 1) показал, что самые высокие значения по показателю площади лесных покрытий имеют Костромская, Тверская и Московская области (рис. 1).

Функционирование лесного сектора экономики региона требует коренной реорганизации, поскольку сегодня основным субъектом в анализируемой сфере выступают предприятия государственной формы собственности, обладающие монополией на природные ресурсы леса, большая часть которого экспортируется, а малый и средний бизнес в анализируемой сфере нахо-

Таблица 1.

Центральный федеральный округ РФ по общей территорией и показателем лесистости на 01.01.2020 г.

\begin{tabular}{|l|c|c|c|c|}
\hline \multicolumn{1}{|c|}{ Области ЦФо } & \multicolumn{2}{|c|}{$\begin{array}{c}\text { площадь покрытых лесной растительностью земель } \\
\text { лесного фонда, в том числе хвойных насаждений тыс.га }\end{array}$} & \multicolumn{2}{|c|}{$\begin{array}{c}\text { израсходовано средств на ведение лесного хозяйства, } \\
\text { тыс. руб. }\end{array}$} \\
\hline Российская Федерация & всего & В \% & всего & $100 \%$ \\
\hline Белгородская область & 521797,00 & $100 \%$ & 63008322,1 & $0,41 \%$ \\
\hline Брянская область & 19,7 & $0,004 \%$ & 258968,6 & $0,63 \%$ \\
\hline Владимирская область & 537,4 & $0,103 \%$ & 396257,1 & $0,82 \%$ \\
\hline Воронежская область & 721,3 & $0,138 \%$ & 518166 & $0,51 \%$ \\
\hline Ивановская область & 86,3 & $0,017 \%$ & 319156,7 & $0,57 \%$ \\
\hline Калужская область & 377,1 & $0,072 \%$ & 358205,7 & $0,53 \%$ \\
\hline Костромская область & 311,8 & $0,060 \%$ & 335789,3 & $0,57 \%$ \\
\hline Курская область & 1887,7 & $0,362 \%$ & 361916,8 & $0,36 \%$ \\
\hline Липецкая область & 27,8 & $0,005 \%$ & 229561,2 & $0,62 \%$ \\
\hline Московская область & 55,4 & $0,011 \%$ & 392438,4 & $4,06 \%$ \\
\hline Орловская область & 763,4 & $0,146 \%$ & 2556365,1 & $0,12 \%$ \\
\hline Рязанская область & 12,3 & $0,002 \%$ & 76808 & $1,01 \%$ \\
\hline Смоленская область & 279 & $0,053 \%$ & 634801,3 & $0,71 \%$ \\
\hline Тамбовская область & 463,6 & $0,089 \%$ & 450451,7 & $0,78 \%$ \\
\hline Тверская область & 154,5 & $0,030 \%$ & 489294,8 & $4,97 \%$ \\
\hline Тульская область & 1876,5 & $0,360 \%$ & 3128658,4 & $2,79 \%$ \\
\hline Ярославская область & 25 & $0,005 \%$ & 1756765,5 & $0,59 \%$ \\
\hline
\end{tabular}

Источник: составлено автором на основе [1] 


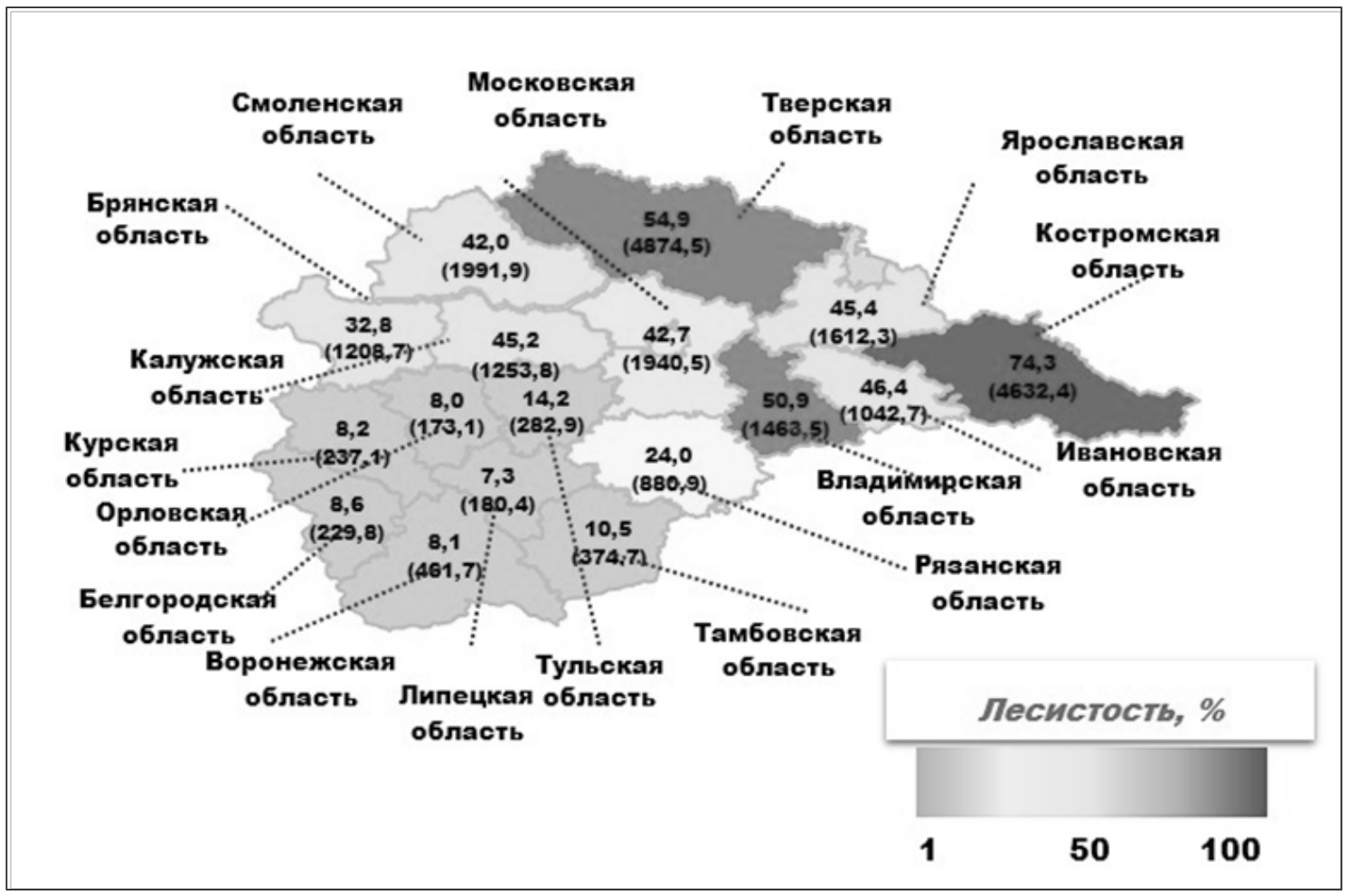

Рис. 1. Лесистость Центрального федерального округа [2]

дится на начальной стадии развития.

Включение предпринимательского сектора в кластерную форму организации производства дало бы толчок к развитию лесного хозяйства и смежных с ним сфер промышленного производства, что со временем повысило бы эффективность использования ресурсов леса и обеспечило его развитие на инновационной основе.

Функционирования кластеров в лесном секторе должно базироваться на рыночных принципах функционирования экономики, при участии субъектов различных организационно-правовых форм хозяйствования, в частности малых и микропредприятий, а также домохозяйств, в частности сельского населения, для которых лес является неотъемлемой частью жизнедеятельности, особенно в центральных районах страны.

Проведенный анализ показал, что в системе лесного фонда ЦФО управления лесного и лесоохотничьего хозяйства выделяют 4 категории лесов, структура которых отражена на диаграмме (рис. 2).

Доля площади рубок леса в ЦФО области составляет только $3 \%$ от общей площади лесов России, из которых 93\% приходится на рубки формирования и оздоровление лесов и 7\% - на рубки главного пользования.

Динамику показателей проведение основных работ в лесном хозяйстве ЦФО за 2019 гг. характеризующие дан- ные таблице 2.

В течение анализируемого периода нарастающая тенденция наблюдалась по показателям «рубки главного пользования» - на 70\%, вместе с этим на 15\% снизился показатель «превращения в покрытые лесной растительностью земли». Более интенсивно проводились рубки формирования и оздоровления лесов и другие мероприятия, связанные с ведением лесного хозяйства, в частности площадь вырубки ликвидной древесины по анализируемым показателем в течение 2017-2019 гг. увеличилась на $35,07 \%$.

В течение анализируемого периода существенного роста претерпела и площадь проведения работ по защите лесов от вредителей и болезней (включая биологические увеличилась на $100 \%$. Положительные сдвиги относительно воспроизведения лесов в лесном фонде обусловлены тем, что лесное хозяйство стало сферой полномочий Министерства аграрной политики РФ, а потому успешнее решается вопрос об облесения деградированных земель, а также балок и оврагов.

Кроме того, ведение лесного хозяйства интенсифицировалось за счет увеличения заготовки ликвидной древесины, в том числе дров, как от рубок главного пользования, так и рубок формирования и оздоровления лесов.

От площади лесов и лесопокрытых участков, а также 


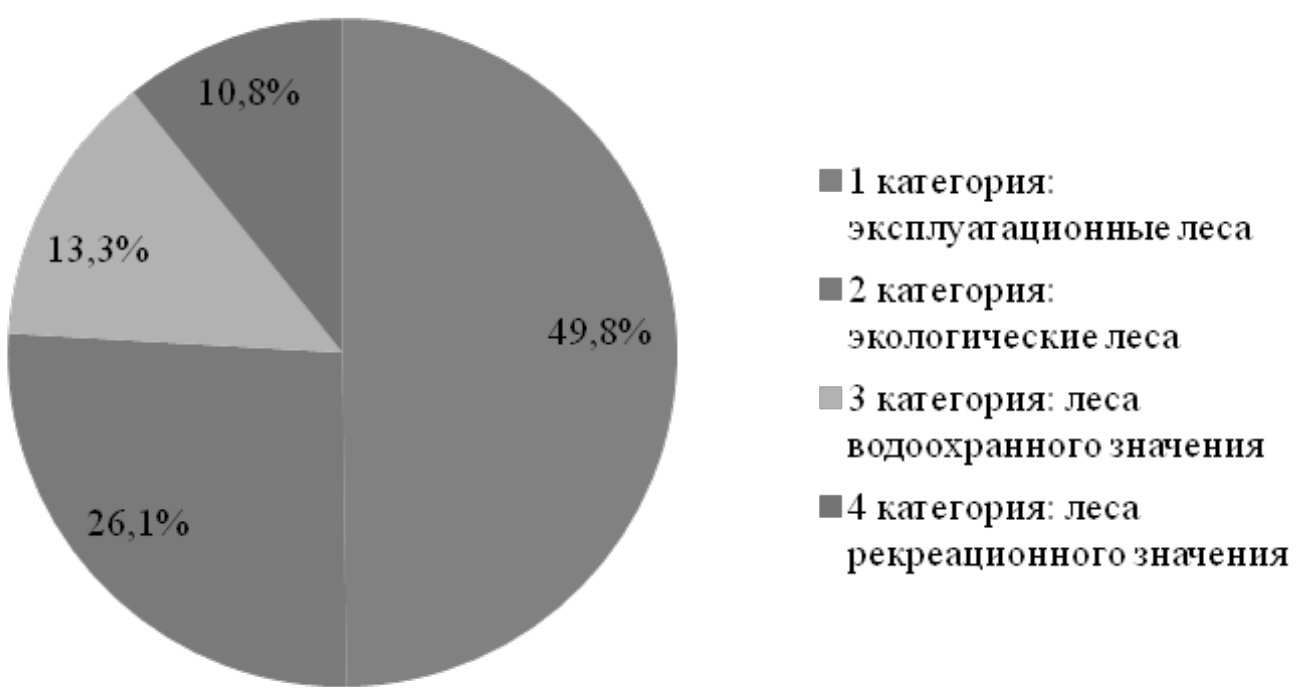

Рис. 2. Структура лесной площади по категориям лесов в системе лесного фонда [3]

Таблица 2.

Проведение основных работ в лесном хозяйстве ЦФО по состоянию на 01.01.2020 г.

\begin{tabular}{|c|c|c|c|c|}
\hline \multirow[t]{2}{*}{ Области ЦФ0 } & \multicolumn{2}{|c|}{$\begin{array}{c}\text { площадь покрытых лесной растительностью земель } \\
\text { лесного фонда, в том числе хвойных насаждений } \\
\text { тыс.га }\end{array}$} & \multicolumn{2}{|c|}{$\begin{array}{c}\text { площадь лесных участков, переданных для заготовки } \\
\text { древесины по договорам купли-продажи } \\
\text { лесных насаждений га }\end{array}$} \\
\hline & всего & В $\%$ & всего & В $\%$ \\
\hline Российская Федерация & 521797,00 & $100 \%$ & 30205,9 & $100 \%$ \\
\hline Белгородская область & 19,7 & $0,004 \%$ & & \\
\hline Брянская область & 537,4 & $0,103 \%$ & & \\
\hline Владимирская область & 721,3 & $0,138 \%$ & & \\
\hline Воронежская область & 86,3 & $0,017 \%$ & 104,7 & $0,35 \%$ \\
\hline Ивановская область & 377,1 & $0,072 \%$ & & $0,00 \%$ \\
\hline Калужская область & 311,8 & $0,060 \%$ & 108,8 & $0,36 \%$ \\
\hline Костромская область & 1887,7 & $0,362 \%$ & 519,4 & $1,72 \%$ \\
\hline Курская область & 27,8 & $0,005 \%$ & 1,1 & $0,00 \%$ \\
\hline Липецкая область & 55,4 & $0,011 \%$ & 145,8 & $0,48 \%$ \\
\hline Московская область & 763,4 & $0,146 \%$ & 45 & $0,15 \%$ \\
\hline Орловская область & 12,3 & $0,002 \%$ & & \\
\hline Рязанская область & 279 & $0,053 \%$ & & \\
\hline Смоленская область & 463,6 & $0,089 \%$ & 91,5 & $0,30 \%$ \\
\hline Тамбовская область & 154,5 & $0,030 \%$ & 11,5 & $0,04 \%$ \\
\hline Тверская область & 1876,5 & $0,360 \%$ & 185,2 & $0,61 \%$ \\
\hline Тульская область & 25 & $0,005 \%$ & 11 & $0,04 \%$ \\
\hline Ярославская область & 546,2 & $0,105 \%$ & 159 & $0,53 \%$ \\
\hline
\end{tabular}

Источник: составлено автором на основе [1] 
площади рубок леса и лесохозяйственных мероприятий, связанных с ведением лесного хозяйства, напрямую зависит заготовка ликвидной древесины.

Перспективным направлением кластеризации в лесном хозяйстве ЦФО является создание кластера (или же отдельной сети в структуре агропромышленного кластера) по заготовке и переработке продукции побочного лесопользование. По экспертным оценкам в ЦФО в заготовке недревесных лесных продуктов участвует каждый второй член домохозяйств горных районов [4], поскольку в пределах природно-экономической зоны существует ряд сравнительных преимуществ относительно наличия отдельных видов лесных ягод на лесных угодьях государственных лесохозяйственных предприятий и природнозаповедного фонда области.

Несмотря на наличие мощного потенциала, государственные лесохозяйственные предприятия (которые сегодня выступают основным субъектом хозяйствования на рынке лесопродукции), не заинтересованы в расширении ассортимента производства и переработки дикорастущих, действенной работе по налаживанию контактов по реализации или переработке лесопродукции [5].

Такая ситуация требует активного привлечения к решение указанных проблем предпринимательского сектора как одного из участников лесопромышленного кластера, в частности к разработке эффективной маркетинговой политики и налаживанию сети по сбору, транспортировке и переработки продукции побочного лесопользования в рамках создаваемого формирование. Необходимым условием эффективного функционирования такой сети должно быть активное вовлечение В этот процесс домохозяйств, что непосредственно заинтересованы в получении дополнительного дохода от деятельности, связанной со сбором дикорастущих и их реализацией на местах.

Следует учитывать и тот факт, что побочное лесопользование имеет в основном сезонный, но стихийный характер, поэтому в пределах создаваемого кластера необходим обустройство плантаций, на которых можно было бы выращивать отдельные виды продукции недревесного происхождения.

В частности, как отмечают отдельные ученые $[6,7$, 8], сбор грибов и ягод в природных условиях и выращивание этих продуктов на плантациях - это два вида деятельности, которые должны сосуществовать и развиваться в каждому лесному хозяйстве, дополняя друг друга.

Стоит отметить, что функционирование лесных кластеров должно базироваться на принципах экологоэкономической деятельности, предусматривающей экологическое ведение лесного хозяйства по всем направлениям деятельности, направленное не только на наращивание эффективности производства, но и на охрану и сохранения окружающей среды.

Экологическое хозяйствование в лесном секторе экономики региона одновременно «будет сопровождаться наращиванием потенциала индустрии отдыха в различных районах области, а также в пределах трансграничных районов, что даст все основания для совместного использования участниками рынка туристических услуг этих регионов имеющегося туристическо-рекреационного потенциала» [9].

Проведенный анализ показал, что в ЦФО существует мощный потенциал для создания нескольких кластеров в лесопромышленном производстве, которые должны быть сориентированы на комплексное взаимодействие всех субъектов в сфере лесного хозяйства с целью эффективного использования имеющихся и потенциальных ресурсов леса, в частности по переработке древесины и производства мебели, деревянного домостроения и по производству альтернативных видов топлива. Перспективным направлением кластеризации в лесном хозяйстве региона является заготовка продукции побочного лесопользования и обеспечения ее переработки на основе интеграции с плодово-ягодными агропромышленными кластерами.

\section{ЛИТЕРАТУРА}

1. Леса России // Федеральное агентство лесного хозяйства. - URL: https://roslesinforg.ru/atlas (дата обращения: 30.07.2020).

2. Бородина 0.Б., Ноговицина Т.Н. Обеспечение защиты права собственности Российской Федерации на земли лесного фонда // Московский экономический журнал. - 2017. - №2. - D0I: 10.24411/2413-046X-2017-10006.

3. Кузнецова Н.Ф., Сауткина М.Ю. Состояние лесов и динамика их породного состава в Центральном федеральном округе // Лесохоз. информ. : электрон. сетевой журн. - 2019. - № 2. - C. 25-45. - URL: http://hi.vniilm.ru (дата обращения: 02.08.2020).

4. Гончаренко Л.П., Воронова Т.А., Сыбачин С.А., Шарко Е.Р. — Применение инновационных технологий производства на предприятиях деревообрабатывающей промышленности России // Теоретическая и прикладная экономика. - 2018. - № 3. - C. 70-87. DOI: 10.25136/2409-8647.2018.3.27199 URL: https://nbpublish.com/library_read_article.php?id=27199

5. Кузнецова Н.Ф. Популяционная неустойчивость хвойных лесов и пути сохранения биоразнообразия лесных древесных видов в Центральном федераль- 
ном округе // Принципы и способы сохранения биоразнообразия: матер. IV В серосс. науч. конф. с междунар. участием МарГУ. - Йошкар-0ла, 2010. - С. 367-370.

6. Гниненко Ю.И., Хегай И.В. Динамика усыхания еловых лесов в Московском регионе // Лесохоз . информ. : электрон.сет.журнал. - 2018. - №2. - С. 65-74. - URL http: //lhi.vnilm.ru/ (дата обращения: 20.07.2020).

7. Багаев С.С., Чудецкий А.И. Результаты рубок ухода в лиственно-еловых насаждениях Костромской области // Лесохоз. информ. : электрон.сет.журнал. 2018. - № 1. - C. 5-20. - URL: http: //lhi.vnilm.ru/ (дата обращения: 20.07.2020).

8. Клейнер Г.Б., Качалов Р.М., Нагрудная Н.Б. Синтез стратегии кластера на основе системно-интеграционной теории // Наука - 0бразование - Инновации. - 2008. - № 7 .

9. Сембер С.В., Матевка Т.В. Кластеры в сфере лесопромышленного производства региона: проблемы и перспективы развития // Вестник НГИЭИ. Экономические науки. - Вып. № 5 (60). - 2016. -С. 67-73.

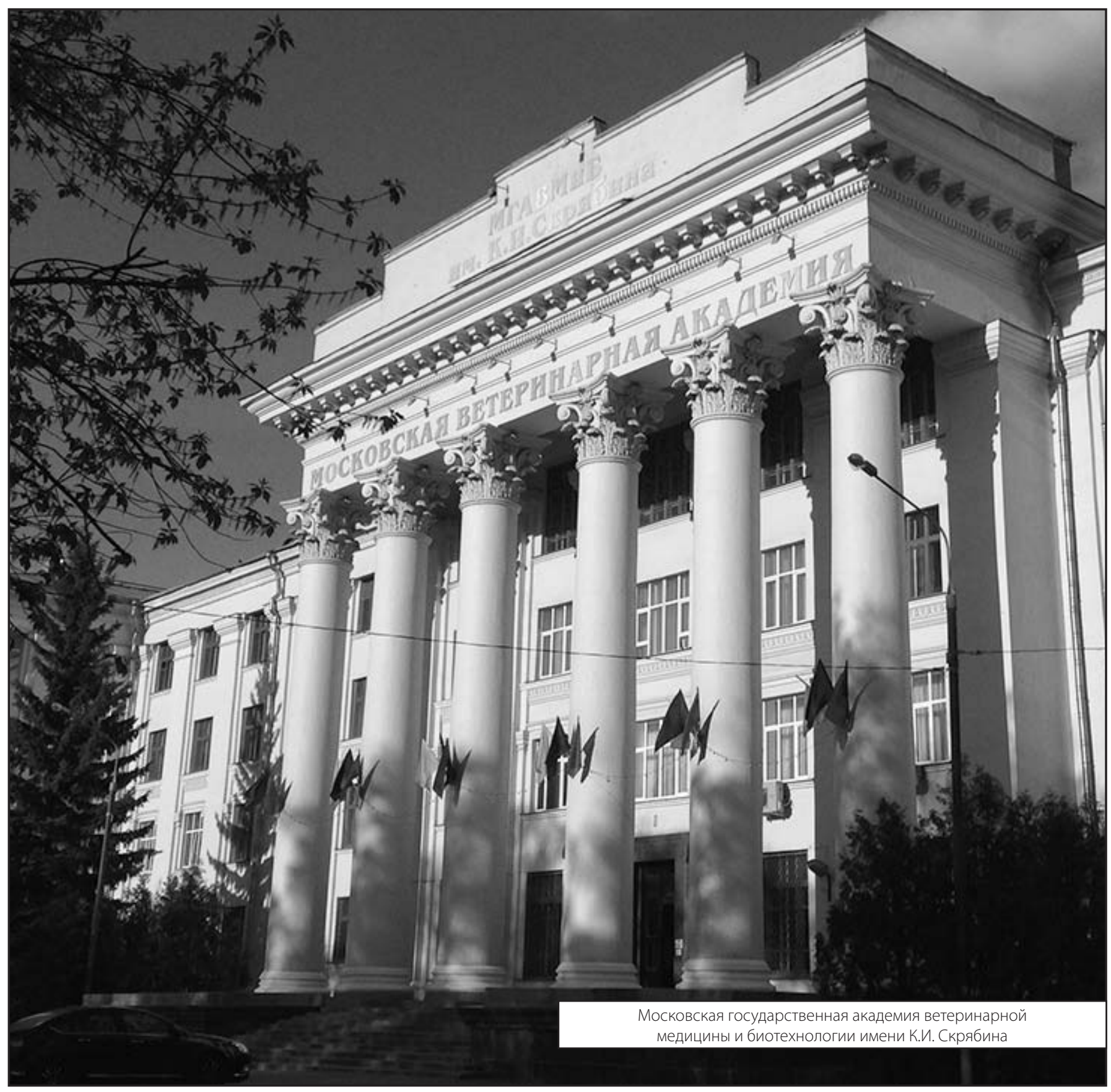

